(online) = ISSN $2285-3642$

ISSN-L = $2285-3642$

Journal of Economic Development, Environment and People

Volume 10, Issue 3, 2021

URL: http://jedep.spiruharet.ro

e-mail: office jedep@spiruharet.ro

\title{
Utility Maximization of Bangladeshi Consumers within Their Budget: A Mathematical Procedure
}

\author{
Haradhan Kumar MOHAJAN \\ Assistant Professor, Department of Mathematics, Premier University, Chittagong, Bangladesh
}

\begin{abstract}
A consumer is considered as a person or a group of people who uses purchased goods, products, or services only for personal use, and not for manufacturing or resale. Consumers usually purchase valuable and useful commodities or goods by spending all or partial of their income. The property of a commodity that enables it to satisfy human wants is called utility. Producers must be conscious to increase the utility among the consumers. This study has considered the maximization of utility problem of consumers of Bangladesh subject to two constraints; namely, budget constraint and coupon constraint. Consequently, in the study two Lagrange multipliers are used and interpreted these with mathematical analysis. Prediction of consumer behavior will help both producers and consumers to take decision of their future economic productions and consumptions, respectively. This article is ornamented with sufficient theorems and economic analyses. So that all the readers find interest when go through the economic analysis of utility maximization.
\end{abstract}

Keywords: Consumer satisfaction, Lagrange multipliers, utility maximization

JEL Codes: C61, D12, H41, I31, O12

How to cite: Mohajan, H. K. (2021). Utility Maximization of Bangladeshi Consumers within Their Budget: A Mathematical Procedure. Journal of Economic Development, Environment and People, 10(3), 60-85. doi:http://dx.doi.org/10.26458/jedep.v10i3.704

\section{Introduction}

Utility is a fundamental concept in economics. The original and modern concept of utility was developed in the late $18^{\text {th }}$ century by the English moral philosopher, jurist, and social reformer, Jeremy Bentham (1748-1832). He provided the philosophy of utilitarianism that took for its fundamental axiom. According to him, utility was the tendency of an object or action to increase or decrease overall happiness. His utility maximization paradigm is always central in the social sciences. His ideas heavily influenced to other classical economists, such as Gossen (1810-1858), Jevons (1835-1882), Marshall (1842-1924), and Edgeworth (1845-1926) [Chisholm, 1911].

Nature has placed humankind under the governance of two sovereign rules; pain and pleasure. The value of a pleasure or pain is considered by it will be greater or lesser according to four conditions; i) intensity, ii) duration, ii) certainty or uncertainty, and iv) propinquity or remoteness. Individuals always

+ Corresponding author. Tel.: +8801716397232 E-mail address: haradhan1971@gmail.com 


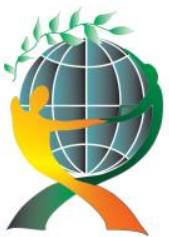

\author{
(online) $=$ ISSN $2285-3642$ \\ ISSN-L = $2285-3642$ \\ Journal of Economic Development, Environment and People \\ Volume 10, Issue 3, 2021 \\ URL: http://jedep.spiruharet.ro \\ e-mail: office jedep@spiruharet.ro
}

struggle to maximize an increasing function of consumption. Utility is the property in any object that produces benefit, advantage, pleasure, good, or happiness (positive utility), i.e., to prevent the happening of mischief, pain, evil, or unhappiness (negative utility) of a particular individual or of a community [Bentham, 1780]. In economics, the consumer is defined as a homo oeconomicus or economic man, whose main characteristics are rationality and only sees his own individual interests. Oeconomicus comes from the Ancient Greek words: oikos which means home and nemein which means management [Mill, 1848; Waterfield, 1990].

If rationality is identified then it is possible to maximize utility. Sometimes individuals fail their utility maximization; consequently, it is not possible for them to act rationally. Hence, mathematical representation of utility maximization is required to obtain better result [Gauthier, 1975]. However, ultimately Bentham's utilitarian project was abandoned in the $19^{\text {th }}$ century economics in favor of rationality and formal definitions of utility, such as rational choice theory. A major reason for this abandonment was that his utility was impossible to measure [Read, 2004]. In modern economics, utility is a measure of a consumer's preferences on an alternative set of commodities or services [Coleman \& Fararo, 1992].

In this study we consider a utility maximization problem of consumers of Bangladesh subject to two constraints; namely, budget constraint and coupon constraint. Let us assume that each consumer of the country has sufficient money, as well as, enough number of coupons to purchase the essential commodities. Bangladesh is a developing country and agriculture is its main source of income. Recently it moves to partial industrialization. Main industrial sector of the country is Garments and textile industry. Recently, Bangladesh is using modern technologies to industries. As a result, the products of Bangladesh become popular to the consumers of the country and abroad. Bangladeshi producers must first target the increase of utility to the local consumers and then they think for global consumers.

\title{
2. Literature Review
}

The literature review is an introductory section that tries to highlight the contributions of other scholars in the same field within the existing knowledge [Polit \& Hungler, 2013]. David Gauthier reviewed that a rational man enters civil society to maximize his expectation of well-being, and morality is that system of principles of action which rational persons collectively adopt to maximize their well-being. To the utilitarian, the rational and moral individual seeks the maximum happiness of mankind by maximizing utility [Gauthier, 1975]. F. Thomas Juster gives a brief history of the development of utility theory, and suggests a revised basic source of utility. He reexamines the role of goods and services that produce utility, and simplifies the conceptual structure at the cost of complicating the measurement problem, as well as, the analytic properties of the system [Juster, 1990]. Qi Zhao and his coauthors have proposed multi-product utility maximization as a general approach to recommendation driven by economic principles. They have also given basic economic relations, such as substitutability and complementarity between products that are crucial for recommendation tasks [Zhao et al., 2017].

Felix Kubler and his coauthors have extended prior analyses by deriving three distinct tests for demands to be rationalized by expected utility; i) a contingent claim analogue to the certainty strong axiom of revealed preference, ii) a characterization of the functional form for demand, and iii) necessary and sufficient conditions based on the Slutsky matrix. They have realized that a consumer's demand can be described as having been derived from utility maximization, subject to a budget constraint [Kubler et al., 2014]. Latizia Alvino and her coauthors have tried to analyze the use of marginal utility theory in Neuromarketing. The marginal utility is essential economic parameter that affects satisfaction, and 


\author{
(online) $=$ ISSN $2285-3642$ \\ ISSN-L = $2285-3642$ \\ Journal of Economic Development, Environment and People \\ Volume 10, Issue 3, 2021 \\ URL: http://jedep.spiruharet.ro \\ e-mail: office jedep@spiruharet.ro
}

economists can measure satisfaction [Alvino at el., 2018]. Ivan Moscati tries for the measurement of utility showing the contrast between ordinal and cardinal views of utility during the period 1870-1960 [Moscati, 2013].

In a study, Jamal Nazrul Islam and his coauthors have applied the technique in multivariable calculus. They have used both necessary and sufficient conditions to determine the maximum utility. The have analyzed the seminal work "Lagrange Multiplier Problems in Economics" of two American scholars: mathematician John V. Baxley and economist John C. Moorhouse. They have used optimization problems in economics with the help of mathematical modeling. In a portion of detail work they have provided the reasonable interpretation of the Lagrange multipliers that contribute techniques of explaining utility maximization properly [Islam et al., 2010]. Pahlaj Moolio and his coauthors very carefully clarified the aim of producers that target optimization of output [Moolio et al., 2009]. Lia Roy and her coauthors have boldly revealed that cost minimization is essential for the sustainable development of an industry [Roy et al., 2021].

Haradhan Kumar Mohajan has considered three inputs, such as capital, labor and other inputs for the sustainable production of a factory of Bangladesh. He is confirmed that for a sustainable production the factories of the country must run efficiently and production rules must follow scientific method [Mohajan, 2021a]. According to him recently Bangladesh moves to industrialization. In a published book he and his coauthors have measured the optimization presentations and have analyzed economics for global social welfare [Mohajan et al., 2013]. In another mathematical economic paper he has investigated the CobbDouglas production function to predict the cost minimization policies of a running garments industry of Bangladesh. By the statistical analysis he shows that the garments sector of Bangladesh has better future if it moves to increasing returns scale production [Mohajan, 2021b]. He has also examined three optimization mathematical models with necessary and sufficient conditions [Mohajan, 2017b].

\title{
3. Methodology of the Study
}

Methodology in any research is the organized and meaningful procedural works that follow scientific methods efficiently [Kothari, 2008]. Research can be classified into three main categories as [Swanson \& Holton, 2005; Creswell, 2011]: 1) quantitative research, 2) qualitative research, and 3) mixed method research. Each of these methods plays important roles in research area. Researchers always follow any one of the three research methods [Mohajan, 2018, 2020]. To prepare a good research, researchers often face various problems in data collection, statistical calculations, and to obtain accurate results. Reliability and validity are also the two most important and fundamental features in the evaluation of any measurement instrument or tool for a good research [Mohajan, 2017c]. In our paper we have depended on the secondary data that are collected from various research papers, books, internet, etc. At the start we have included some very easy type definitions related to the article, such as indifference curve, utility, utility function, cardinal utility, ordinal utility, marginal utility, price vector and budget constraint, and comparative static analysis. Then we set a mathematical economic model of utility function for three commodities by introducing two Lagrange multipliers $\gamma_{1}$ and $\gamma_{2}$, where we have considered 5-dimensional unconstrained problem that maximized utility function. In the study we have used techniques of calculus and matrix algebra. To clarify this model we have tried to display an illustrative economic example where we have considered only two commodities. 


\author{
(online) $=$ ISSN $2285-3642$ \\ ISSN-L = $2285-3642$ \\ Journal of Economic Development, Environment and People \\ Volume 10, Issue 3, 2021 \\ URL: http://jedep.spiruharet.ro \\ e-mail: office jedep@spiruharet.ro
}

Then we have explained the behavior and importance of two Lagrange multipliers. We have taken a step to verify the utility maximization is possible or not. With a detail mathematical analysis we have abled to verify that utility maximization is possible, where we have used the properties of non-singular Hessian and Jacobian. Finally, we have tried to predict the economic relations by using the comparative statics for the welfare of both producers and consumers. In this study we have included sufficient theorems and economic analyses to make the paper interesting to the readers.

\title{
4. Objective of the Study
}

The key objective of this study is to show the utility maximization policy among the consumers of Bangladesh. If the producer can create a strong satisfaction of the products within the society, he/she can obtain a maximum profit, and can create a sustainable atmosphere in the economy. The other supportive objectives of the study are as follows:

- to provide a suitable mathematical model for utility maximization to the Bangladeshi consumers,

- to verify optimization by sufficient condition, and

- to offer economic prediction for the proper choice of commodities for maximization of utility.

\section{Some Basis Ideas on Utility}

We have used knowledge and necessary materials from both mathematics and economics to prepare this article. We have realized that all the readers are not efficient in both subjects. Thinking for the common readers we have used some definitions related to the utility. Those who have enough knowledge on these definitions can skip this section and study the main text confidently.

\subsection{Indifference Curves}

In economics, an indifference curve (IC) is a collection of all commodity bundles which provide the consumer with the same level of utility. Therefore, an IC connects points on a graph representing different quantities of two goods, where a consumer is indifferent among all points on this curve. The theory of ICs was developed by Anglo-Irish philosopher and political economist Francis Ysidro Edgeworth (1845-1926) in 1881; later on, Vilfredo Federico Damaso Pareto (1848-1923), an Italian economist, sociologist, civil engineer, political scientist, and philosopher was the first author to actually draw the ICs [Marshall, 1881]. The ICs were popularized and greatly extended of application in the 1930s by two other English economists; R. G. D. Allen and John R. Hicks [Hicks, 1932].

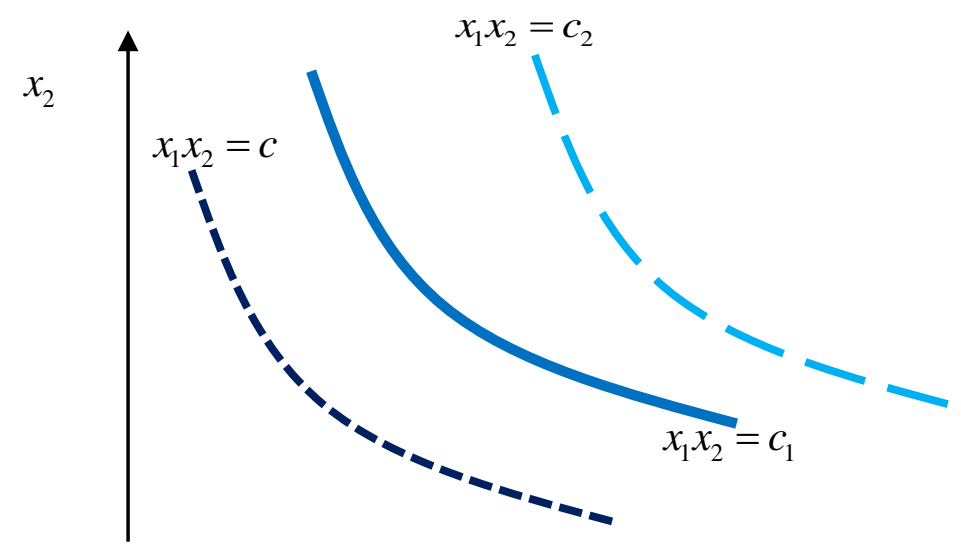




\author{
(online) $=$ ISSN $2285-3642$ \\ ISSN-L = $2285-3642$ \\ Journal of Economic Development, Environment and People \\ Volume 10, Issue 3, 2021 \\ URL: http://jedep.spiruharet.ro \\ e-mail: office jedep@spiruharet.ro
}

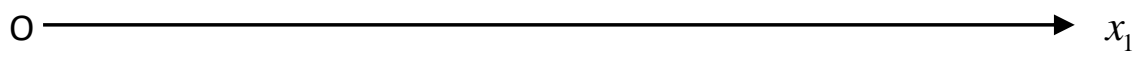

Figure 1: The rectangular hyperbolae lying in the positive quadrant with $0<c<c_{1}<c_{2}$.

The curves in the $x_{1} x_{2}$-plane are given by; $u\left(x_{1}, x_{2}\right)=c, u\left(x_{1}, x_{2}\right)=c_{1}$, and $u\left(x_{1}, x_{2}\right)=c_{2}$ where $0<c<c_{1}<c_{2}$ (say). Here,

$$
x_{1} x_{2}=c, x_{1} x_{2}=c_{1} \text {, and } x_{1} x_{2}=c_{2}
$$

are rectangular hyperbolae (Figure 1). In 3-dimensional case,

$$
x_{1} x_{2} x_{3}=c, x_{1} x_{2} x_{3}=c_{1} \text {, and } x_{1} x_{2} x_{3}=c_{2}
$$

are called rectangular hyperboloid. The individual is indifferent to the bundles represented by points on the same curve [Mohajan, 2017a]. These types of curves are called ICs which do not intersect each other, and are used to describe the preference relationship between a desirable pair of products. A higher IC refers to a higher level of satisfaction, and consequently, a lower IC refers to less satisfaction [Allen, 1934].

\title{
5.2. Utility in Economics
}

We can define the utility as the total satisfaction received by consumers from consuming a commodity. As individuals consume more of a good per time period, their total utility increases, but their marginal utility diminishes. In economics, consumers always try to maximize their utility by spending their income. Utility is important in economics, as it directly influences the demand and supply [Fishburn, 1970]. Utility helps consumers for understanding how to maximize their utility by allocating their money between multiple types of goods and services, as well as, helps companies for understanding how to structure tiered pricing [Stigler, 1950].

\subsection{Utility Function}

In the middle and late of the $19^{\text {th }}$ century some economists thought that utility can be measured like length, mass or temperature. But no one has yet succeeded in defining an objective unit of utility. Now we can easily measure the utility.

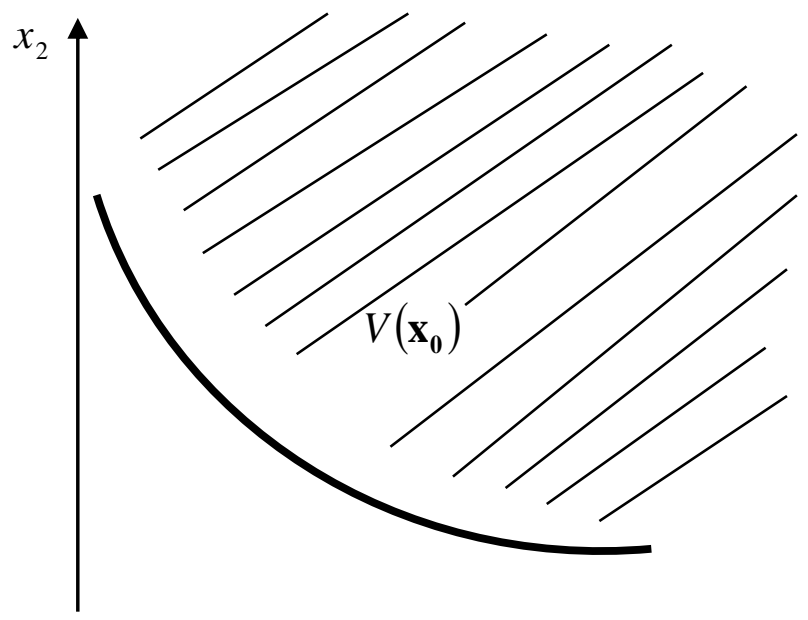


(online) $=$ ISSN $2285-3642$

ISSN-L = $2285-3642$

Journal of Economic Development, Environment and People

Volume 10, Issue 3, 2021

URL: http://jedep.spiruharet.ro

e-mail: office jedep@spiruharet.ro

\section{$\mathrm{O}$}

Figure 2: The convex set $V\left(x_{0}\right)$ is the shaded region.

Let, $X$ be a consumption set and a consumer's utility function is, $u: X \rightarrow R$. If $u_{\alpha}\left(x_{1}\right)$ and $u_{\alpha}\left(x_{2}\right)$ be the numerical values of utility of an individual $\alpha$ to the alternatives $x_{1}, x_{2} \in X$ then $u_{\alpha}\left(x_{1}\right) \geq u_{\alpha}\left(x_{2}\right)$ implies $u\left(x_{1}\right) \geq u\left(x_{2}\right)$ [Cassels, 1981]. If $u_{\alpha}(x)$ and $u_{\alpha}(y)$ be the numerical values of utility of an individual $\alpha$ to the alternatives $x, y \in Y$ then $u_{\alpha}(x) \geq u_{\alpha}(y)$ implies $x R_{\alpha} y$. The utility of individual $\alpha$ could be transformed without altering its preference representation property. If we define another utility function of individual $\alpha$ in terms of $u_{\alpha}$ by $v_{\alpha}=u_{\alpha}+c$, where $c$ is any constant, then $v_{\alpha}(x) \geq v_{\alpha}(y)$. This transformation is called monotone transformation. If a utility function represents a person's preferences, any monotone transformation of that utility function is another utility function that represents the some preferences. We now define the utility function as [Islam et al., 2009a, b],

$$
u(x)=u\left(x_{1}, x_{2}, \ldots, x_{n}\right)
$$

In preference relation we can write;

$$
u(x)>u(y) \Leftrightarrow x P y .
$$

Let us consider a fixed vector $x_{0}$, and consider the set of all the vectors $x$ which are preferred to $x_{0}$. If we denote this set by $V\left(x_{0}\right)$ (Figure 2), we can write [Cassels 1981],

$$
V\left(x_{0}\right)=\left\{x: x P x_{0}\right\} \text {. }
$$

For the utility function (5) can be written as,

$$
V\left(x_{0}\right)=\left\{x: u(x)>u\left(x_{0}\right)\right\} .
$$

\subsection{Cardinal Utility}

Cardinal utility is a single good approach and first successfully introduced by English economist, Alfred Marshel (1842-1924). From 1870 to 1910, William Stanley Jevons, Carl Menger, Léon Walras, and some other early economists treated individual utility as cardinally measurable [Moscati, 2013]. Cardinal utility indicates that the utilities obtained from consumption can be measured and ranked objectively, and can be represented by numbers, such as $1,2,3, \ldots, n$. For example, if one $\mathrm{kg}$ of mango has utility of 200 utils, and one $\mathrm{kg}$ of apple has utility of 400 utils, then cardinal utility indicates that an apple (of $100 \mathrm{~g}$ ) gives utility equals to two mangoes (of 100g each) [Dominick, 2008]. In economics, a cardinal utility function is a utility index that preserves preference orderings uniquely up to positive affine transformation. Two utility functions $U(x)$ and $V(x)$ can be related by,

$$
U(x)=c V(x)+d
$$

where $c$ and $d$ are constants [Strotz, 1953]. Cardinal utility is dominated until the $20^{\text {th }}$ century. It has no universal scale, and the factors that determine the values of utility in a given situation are subjective and might vary from one consumer to the other, i.e., interpersonal comparisons of cardinal utility are usually meaningless [Kirsh, 2017]. 


\author{
(online) $=$ ISSN $2285-3642$ \\ ISSN-L = $2285-3642$ \\ Journal of Economic Development, Environment and People \\ Volume 10, Issue 3, 2021 \\ URL: http://jedep.spiruharet.ro \\ e-mail: office jedep@spiruharet.ro
}

\title{
5.5. Ordinal Utility
}

Ordinal utility is a multi-good approach and only ranks the utility received from consuming various amounts of a commodity or a bundle of commodities. In economics, an ordinal utility indicates the preference relation that identifies which option is better than the other. The ordinal utility concept was first introduced by Pareto in 1906 [Pareto, 1906]. Later, it was developed by British economist Sir John Hicks (1904-1989) and English economist, mathematician and statistician, Sir Roy George Douglas Allen (1906-1983). It does not give actual numbers over different bundles but ranks utilities received from different bundles of goods. It is useful for explaining the law of diminishing marginal utility and fundamental economic laws of supply and demand. For example, there are three fruits apple $(A)$, mango $(M)$, and orange $(O)$. An individual can prefer apple to mango and mango to orange. We can express this relation by ordinal utility as, $U(A) \succ U(M) \succ U(O)$ [Dominick, 2008].

\subsection{Marginal Utility}

Marginal utility (MU) is defined as the extra utility gained from the consumption of one additional unit of a good. It measures the slope of the utility function with respect to the units changed in one commodity. If an individual consumes more of a good per time period, his/her total utility increases, but marginal utility diminishes [Castro \& Araujo, 2019]. The concept of MU was proposed by Italian economist Ferdinando Galiani (1728-1787), who studied the central role of utility and scarcity [Galiani, 1751]. The MU of commodity $X$ is,

$$
M U=\frac{\Delta U}{\Delta X} .
$$

The property $M U>0$ indicates that the commodity brings additional happiness, $M U=0$ provides no extra happiness, and $M U<0$ offers more consumption is harmful [Lin \& Peng, 2019]. Let a person maximizes his/her pleasure by spending entire income for various enjoyments. If $M U_{k}$ be the marginal utility of commodity $k$, and $P_{k}$ be its price, then for all $k$ [Georgescu-Roegen, 1968],

$$
\frac{M U_{1}}{P_{1}}=\frac{M U_{2}}{P_{2}}=\ldots=\frac{M U_{k}}{P_{k}} .
$$

The MU is defined by, $U^{\prime}(x)>0$, the law of diminishing marginal utility is a decreasing function of the quantity consumed, i.e., $U^{\prime \prime}(x)<0$. For example, a thirsty person will drink a cold drink can with full satisfaction, but a second can will take less eagerly [McConnell et al., 2009].

\subsection{Price Vector and Budget Constraint}

Let us consider a bundle of two commodities, so that $\left(x_{1}, x_{2}\right)$ represents a bundle of $x_{1} \mathrm{~kg}$ of rice, and $x_{2} \mathrm{~kg}$ of wheat (say). Let $p_{1}$ be the cost of $1 \mathrm{~kg}$ of rice, and $p_{2}$ be the cost of $1 \mathrm{~kg}$ of wheat in dollar. We call $\mathbf{p}=\left(p_{1}, p_{2}\right)$ the price vector of possible bundles of rice and wheat. The total cost of the bundle $x_{1}, x_{2}$ is given by;

$$
p_{1} x_{1}+p_{2} x_{2}=\mathbf{p . x}
$$




\author{
(online) $=$ ISSN $2285-3642$ \\ ISSN-L = 2285 - 3642 \\ Journal of Economic Development, Environment and People \\ Volume 10, Issue 3, 2021 \\ URL: http://jedep.spiruharet.ro \\ e-mail: office jedep@spiruharet.ro
}

where $\mathbf{p . x}$ is a scalar product of vectors $\mathbf{p}$ and $\mathbf{x}$. We now introduce the idea of a budget constraint. For bundle $\mathbf{x}$ with a price vector $\mathbf{p}$ let us consider one has maximum $c$ amount of dollars to spend, then we can write,

$$
\text { p. } \mathbf{x} \leq c ;(\mathbf{p} . \mathbf{x} \text { is the price of the bundle } \mathbf{x})
$$

which is referred to as budget constraint. Let us consider the hypersurfaces

$$
u(x)=\text { constant }
$$

for various values of the constant. According to (1), the individual concerned is indifferent to the bundles represented by all these vectors, i.e., all these bundles for him are 'equally good' (or 'equally bad'). That is why (2) are indifferent hypersurfaces. For simplicity we consider $n=2$, so,

$$
u(\mathbf{x})=x_{1} x_{2} .
$$

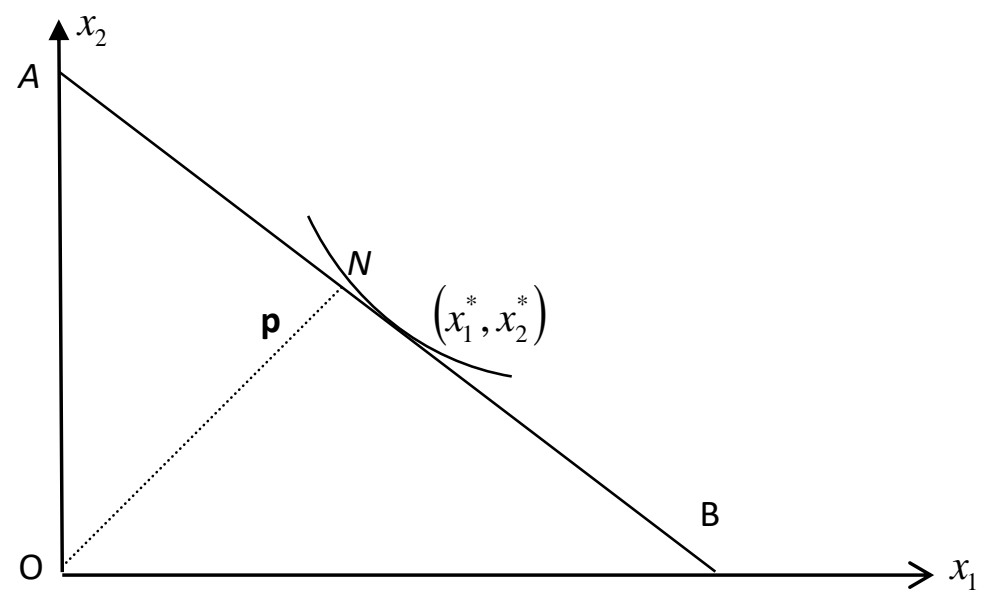

Figure 3: The point $\left(x_{1}^{*}, x_{2}^{*}\right)$ maximizes the utility. $O N$ is parallel to price vector $\mathbf{p}$ which is perpendicular to $A B$.

The ICs are given by rectangular hyperbolae,

$$
x_{1} x_{2}=k
$$

where, $k=$ constant $>0$.

Let the fixed price vector be $\mathbf{p}=\left(p_{1}, p_{2}\right)$, then by (11) the budget constraint is,

$$
p_{1} x_{1}+p_{2} x_{2} \leq c
$$

with fixed $c$. If we draw a straight line $(A B)$,

$$
p_{1} x_{1}+p_{2} x_{2}=c
$$

then there is only one member of family of indifference curves (14) that touches the straight line (16).

\title{
5.8. Comparative Static Analysis
}

In the society the behavior of the buyers and sellers often changes, which causes the shift of the demand and supply curves to itself over time. In economic, it is important to analyze how these shifts affect equilibrium. This analysis is called comparative static analysis. Comparative statics results are usually derived by using the implicit function theorem to calculate a linear approximation to the system of 


\author{
(online) $=$ ISSN $2285-3642$ \\ ISSN-L = 2285 - 3642 \\ Journal of Economic Development, Environment and People \\ Volume 10, Issue 3, 2021 \\ URL: http://jedep.spiruharet.ro \\ e-mail: office jedep@spiruharet.ro
}

equations that defines the equilibrium, under the assumption that the equilibrium is stable. For example, if $P$ be the price of a commodity $X$, then $\frac{\partial X}{\partial P}<0$ indicates that if the price of commodity $X$ increases, the level of consumption of $X$ will decrease [Islam et al., 2011].

\title{
6. Economic Model of Utility
}

Let us consider three commodities; $x_{1}, x_{2}$, and $x_{3}$ that are available in the market and any consumer can purchase these within his/her budget. An individual consumer wants to purchase only $X_{1}, X_{2}$, and $X_{3}$ amounts from these three commodities $x_{1}, x_{2}$, and $x_{3}$, respectively. We suppose that the customer wants to spend all of his/her income to purchase of these three commodities and also submits all of his/her coupons. Let us consider a utility function [Islam et al., 2010],

$$
U=U\left(X_{1}, X_{2}, X_{3}\right)
$$

An honest and legal consumer wants to maximize his/her utility subject to two constraints; budget constraint and coupon constraint. Now budget constraint of the consumer can be represented as,

$$
B=P_{1} X_{1}+P_{2} X_{2}+P_{3} X_{3}
$$

where $P_{1}, P_{2}$ and $P_{3}$ are the prices of per unit of commodity of $x_{1}, x_{2}$, and $x_{3}$, respectively. Also his/her coupon constraint can be represented as,

$$
R=r_{1} X_{1}+r_{2} X_{2}+r_{3} X_{3}
$$

where $r_{1}, r_{2}$, and $r_{3}$ are the coupons required in order to purchase a unit of commodity $x_{1}, x_{2}$, and $x_{3}$, respectively.

Now we introduce two Lagrange multipliers $\gamma_{1}$ and $\gamma_{2}$ as devices of optimization procedures. We use (18) and (19) to represent the Lagrangian function $V$ as,

$$
\begin{gathered}
V\left(X_{1}, X_{2}, X_{3}, \gamma_{1}, \gamma_{2}\right)=U\left(X_{1}, X_{2}, X_{3}\right)+\gamma_{1}\left(B-P_{1} X_{1}-P_{2} X_{2}-P_{3} X_{3}\right) \\
+\gamma_{2}\left(R-r_{1} X_{1}-r_{2} X_{2}-r_{3} X_{3}\right) .
\end{gathered}
$$

Equation (20) is a 5-dimensional unconstrained problem that maximized utility function. Now we apply the partial derivatives of (20), and for utility maximization we set them equal to zero as follows:

$$
\begin{aligned}
& V_{\gamma_{1}}=B-P_{1} X_{1}-P_{2} X_{2}-P_{3} X_{3}=0, \\
& V_{\gamma_{2}}=R-r_{1} X_{1}-r_{2} X_{2}-r_{3} X_{3}=0, \\
& V_{1}=U_{1}-\gamma_{1} P_{1}-\gamma_{2} r_{1}=0, \\
& V_{2}=U_{2}-\gamma_{1} P_{2}-\gamma_{2} r_{2}=0, \\
& V_{3}=U_{3}-\gamma_{1} P_{3}-\gamma_{2} r_{3}=0,
\end{aligned}
$$

where $V_{\gamma_{1}}=\frac{\partial V}{\partial \gamma_{1}}, U_{1}=\frac{\partial U}{\partial X_{1}}$, etc. represent partial derivatives. From (21a-e) we get the optimal solutions $X_{1}^{*}, X_{2}^{*}, X_{3}^{*}, \gamma_{1}^{*}$, and $\gamma_{2}{ }^{*}$ each quantity being a function of the parameters $P_{1}, P_{2}, P_{3}, r_{1}, r_{2}$, and $r_{3}$, 


\author{
(online) $=$ ISSN $2285-3642$ \\ ISSN-L = $2285-3642$ \\ Journal of Economic Development, Environment and People \\ Volume 10, Issue 3, 2021 \\ URL: http://jedep.spiruharet.ro \\ e-mail: office jedep@spiruharet.ro
}

and also of $B$ and $R$. Now we consider the infinitesimal changes $d X_{1}, d X_{2}$, and $d X_{3}$ of commodities $X_{1}$, $X_{2}$, and $X_{3}$, respectively. Since, $U=U\left(X_{1}, X_{2}, X_{3}\right), B=B\left(X_{1}, X_{2}, X_{3}\right)$, and $R=R\left(X_{1}, X_{2}, X_{3}\right)$, now we apply the infinitesimal changes in $U, B$, and $R$, then we can write,

$$
\begin{aligned}
& d U=U_{1} d X_{1}+U_{2} d X_{2}+U_{3} d X_{3}, \\
& d B=P_{1} d X_{1}+P_{2} d X_{2}+P_{3} d X_{3}, \\
& d R=r_{1} d X_{1}+r_{2} d X_{2}+r_{3} d X_{3} .
\end{aligned}
$$

In the following theorem we will see that the two Lagrange multipliers' contributions for the utility maximization of the consumers' of Bangladesh.

Theorem 1: Prove that the Lagrange multipliers, $\gamma_{1}$ and $\gamma_{2}$, give the changes in the utility resulting to one of the constraints being operative, but not the other.

Proof: Now we consider that the budget of a particular project is fixed (constant), then $d B=0$, we consider for this project $\gamma_{1}=0$. From (21c) we get,

$$
U_{1}-\gamma_{2} r_{1}=0 \Rightarrow \frac{U_{1}}{r_{1}}=\gamma_{2} \text {. }
$$

From (21d) we get,

$$
U_{2}-\gamma_{2} r_{2}=0 \Rightarrow \frac{U_{2}}{r_{2}}=\gamma_{2}
$$

From (21e) we get,

$$
U_{3}-\gamma_{3} r_{3}=0 \Rightarrow \frac{U_{3}}{r_{3}}=\gamma_{2} .
$$

Now dividing (22a) by (22c) we get,

$$
\frac{d U}{d R}=\frac{U_{1} d X_{1}+U_{2} d X_{2}+U_{3} d X_{3}}{r_{1} d X_{1}+r_{2} d X_{2}+r_{3} d X_{3}}
$$

Let us consider $X_{2}=$ constant and $X_{3}=$ constant, then $d X_{2}=0$ and $d X_{3}=0$; at this situation equation (24) becomes,

$$
\frac{d U}{d R}=\frac{U_{1} d X_{1}}{r_{1} d X_{1}}=\frac{U_{1}}{r_{1}}=\gamma_{2}, \text { by (24a). }
$$

Now we consider $X_{1}=$ constant and $X_{3}=$ constant, then $d X_{1}=0$ and $d X_{3}=0$; at this situation equation (24) becomes,

$$
\frac{d U}{d R}=\frac{U_{2} d X_{2}}{r_{2} d X_{2}}=\frac{U_{2}}{r_{2}}=\gamma_{2}, \text { by (24b). }
$$

Let us consider $X_{1}=$ constant and $X_{2}=$ constant, then $d X_{1}=0$ and $d X_{2}=0$; at this situation equation (24) becomes,

$$
\frac{d U}{d R}=\frac{U_{3} d X_{3}}{r_{3} d X_{3}}=\frac{U_{3}}{r_{3}}=\gamma_{2} \text {, by (24c). }
$$




\author{
(online) $=$ ISSN $2285-3642$ \\ ISSN-L = $2285-3642$ \\ Journal of Economic Development, Environment and People \\ Volume 10, Issue 3, 2021 \\ URL: http://jedep.spiruharet.ro \\ e-mail: office jedep@spiruharet.ro
}

Hence, from (25a-c) we see that the Lagrange multiplier $\gamma_{2}$ may be interpreted as,

$$
\left(\frac{\partial U}{\partial R}\right)_{B=\text { constant }}=\gamma_{2} \text {. }
$$

Now we consider that the coupon of a particular project is fixed (constant), then $d R=0$, for this project $\gamma_{2}=0$. From (21c) we get,

$$
U_{1}-\gamma_{1} P_{1}=0 \quad \Rightarrow \frac{U_{1}}{P_{1}}=\gamma_{1}
$$

From (21d) we get,

$$
U_{2}-\gamma_{1} P_{2}=0 \Rightarrow \frac{U_{2}}{P_{2}}=\gamma_{1}
$$

From (21d) we get,

$$
U_{3}-\gamma_{1} P_{3}=0 \Rightarrow \frac{U_{3}}{P_{3}}=\gamma_{1} .
$$

Now dividing (22a) by (22b) we get,

$$
\frac{d U}{d B}=\frac{U_{1} d X_{1}+U_{2} d X_{2}+U_{3} d X_{3}}{P_{1} d X_{1}+P_{2} d X_{2}+P_{3} d X_{3}}
$$

Let us consider $X_{2}=$ constant and $X_{3}=$ constant, then $d X_{2}=0$ and $d X_{3}=0$; and hence (28) becomes,

$$
\frac{d U}{d B}=\frac{U_{1} d X_{1}}{P_{1} d X_{1}}=\frac{U_{1}}{P_{1}}=\gamma_{1}, \text { by }(27 \mathrm{a}) .
$$

Now we consider $X_{1}=$ constant and $X_{3}=$ constant, then $d X_{1}=0$ and $d X_{3}=0$, and hence (28) becomes,

$$
\frac{d U}{d B}=\frac{U_{2} d X_{2}}{P_{2} d X_{2}}=\frac{U_{2}}{P_{2}}=\gamma_{1}, \text { by (27b). }
$$

Let us consider $X_{1}=$ constant and $X_{2}=$ constant, then $d X_{1}=0$ and $d X_{2}=0$, and hence (28) becomes,

$$
\frac{d U}{d B}=\frac{U_{3} d X_{3}}{P_{3} d X_{3}}=\frac{U_{3}}{P_{3}}=\gamma_{1} \text {, by (27c). }
$$

Hence, from (29a-c) we see that the Lagrange multiplier $\gamma_{1}$ may be interpreted as $\left(\frac{\partial U}{\partial B}\right)_{R=\text { constant }}=\gamma_{1}$. Therefore, the two Lagrange multipliers $\gamma_{1}$ and $\gamma_{2}$ in this specific illustration, give the changes in the utility consequent to one of the constraints being operative, but not the other. Hence, the theorem is proved.

\title{
7. An Illustrative Economic Example
}

If we consider three commodities then our procedures will be very complicated. So that in this example we consider a two-commodity world, where an individual consumer obtains his utility from the 


\author{
(online) $=$ ISSN $2285-3642$ \\ ISSN-L = 2285 - 3642 \\ Journal of Economic Development, Environment and People \\ Volume 10, Issue 3, 2021 \\ URL: http://jedep.spiruharet.ro \\ e-mail: office jedep@spiruharet.ro
}

consumption of two types of commodities $x_{1}$ and $x_{2}$ that are purchased in the marketplace and he/she consumes the quantities of $X_{1}$ and $X_{2}$, respectively. Therefore, the utility function $U\left(X_{1}, X_{2}\right)$ can be written as [Islam et al., 2010],

$$
U=U\left(X_{1}, X_{2}\right)=X_{1} X_{2}
$$

Using (30) in (20) we get,

$$
V\left(X_{1}, X_{2}, \gamma_{1}, \gamma_{2}\right)=X_{1} X_{2}+\gamma_{1}\left(B-P_{1} X_{1}-P_{2} X_{2}\right)+\gamma_{2}\left(R-r_{1} X_{1}-r_{2} X_{2}\right)
$$

For maximization we can write from (31) the first order partial derivatives equal to zero,

$$
\begin{aligned}
& V_{\gamma_{1}}=B-P_{1} X_{1}-P_{2} X_{2}=0, \\
& V_{\gamma_{2}}=R-r_{1} X_{1}-r_{2} X_{2}=0, \\
& V_{1}=X_{2}-\gamma_{1} P_{1}-\gamma_{2} r_{1}=0, \\
& V_{2}=X_{1}-\gamma_{1} P_{2}-\gamma_{2} r_{2}=0 .
\end{aligned}
$$

In the following theorem we want to prove that maximum consumption of commodities can be possible and these are determined by the mathematical procedures.

Theorem 2: Prove that:

a) The maximum consumption of two commodities $X_{1}$ and $X_{2}$ can be expressed as;

$$
X_{1}^{*}=\frac{B r_{2}-P_{2} R}{P_{1} r_{2}-P_{2} r_{1}} \text { and } X_{2}^{*}=\frac{P_{1} R-B r_{1}}{P_{1} r_{2}-P_{2} r_{1}} \text {. }
$$

b) For a maximum utility two Lagrange multipliers can be expressed as;

c) The maximum utility function can be expressed as;

$$
\gamma_{1}^{*}=\frac{R P_{1} r_{2}+R P_{2} r_{1}-2 B r_{1} r_{2}}{\left(P_{1} r_{2}-P_{2} r_{1}\right)^{2}} \text { and } \gamma_{2}^{*}=\frac{B P_{1} r_{2}-R P_{1} P_{2}+B P_{2} r_{1}}{\left(P_{1} r_{2}-P_{2} r_{1}\right)^{2}} \text {. }
$$

Proof: From (32c) we get,

$$
U^{*}=\frac{B R\left(P_{1} r_{2}+P_{2} r_{1}\right)-B^{2} r_{1} r_{2}-P_{1} P_{2} R^{2}}{\left(P_{1} r_{2}-P_{2} r_{1}\right)^{2}} .
$$

$$
\begin{aligned}
& X_{2}=\gamma_{1} P_{1}+\gamma_{2} r_{1} \\
& \Rightarrow \gamma_{1}=\frac{X_{2}-\gamma_{2} r_{1}}{P_{1}} \text { and } \gamma_{2}=\frac{X_{2}-\gamma_{1} P_{1}}{r_{1}} .
\end{aligned}
$$

From (32d) we get,

$$
\begin{aligned}
& X_{1}=\gamma_{1} P_{2}+\gamma_{2} r_{2} \\
& \Rightarrow \gamma_{1}=\frac{X_{1}-\gamma_{2} r_{2}}{P_{2}} \text { and } \gamma_{2}=\frac{X_{1}-\gamma_{1} P_{2}}{r_{2}} .
\end{aligned}
$$

From $(33 a, b)$ only taking values of $\gamma_{1}$ we get,

$$
\frac{X_{2}-\gamma_{2} r_{1}}{P_{1}}=\frac{X_{1}-\gamma_{2} r_{2}}{P_{2}}
$$




$$
\begin{aligned}
& \gamma_{2}\left(P_{1} r_{2}-P_{2} r_{1}\right)=P_{1} X_{1}-P_{2} X_{2} \\
& \gamma_{2}=\frac{P_{1} X_{1}-P_{2} X_{2}}{P_{1} r_{2}-P_{2} r_{1}}, \text { where } P_{1} r_{2}-P_{2} r_{1} \neq 0 .
\end{aligned}
$$

From $(32 a, b)$ only taking values of $\gamma_{2}$ we get,

$$
\begin{aligned}
& \frac{X_{2}-\gamma_{1} P_{1}}{r_{1}}=\frac{X_{1}-\gamma_{1} P_{2}}{r_{2}} \\
& \gamma_{1}\left(P_{1} r_{2}-P_{2} r_{1}\right)=X_{2} r_{2}-X_{1} r_{1} \\
& \gamma_{1}=\frac{X_{2} r_{2}-X_{1} r_{1}}{P_{1} r_{2}-P_{2} r_{1}}, \text { where } P_{1} r_{2}-P_{2} r_{1} \neq 0 .
\end{aligned}
$$

From (32a) we get,

$$
P_{1} X_{1}=B-P_{2} X_{2}
$$

From (33a) and (35) we get,

$$
\gamma_{2}=\frac{B-2 P_{2} X_{2}}{P_{1} r_{2}-P_{2} r_{1}}, \text { where } P_{1} r_{2}-P_{2} r_{1} \neq 0 .
$$

Again from (32b) we get,

$$
r_{2} X_{2}=R-r_{1} X_{1}
$$

From (33b) and (20) we get,

$$
\gamma_{1}=\frac{R-2 X_{1} r_{1}}{P_{1} r_{2}-P_{2} r_{1}}, \text { where } P_{1} r_{2}-P_{2} r_{1} \neq 0 .
$$

Using the value of $X_{1}$ from (35) in (37) we get,

$$
\begin{aligned}
& r_{2} X_{2}=R-r_{1}\left(\frac{B-P_{2} X_{2}}{P_{1}}\right) \\
& r_{2} X_{2}=\frac{P_{1} R-B r_{1}+P_{2} X_{2} r_{1}}{P_{1}} \\
& X_{2}^{*}=X_{2}=\frac{P_{1} R-B r_{1}}{P_{1} r_{2}-P_{2} r_{1}}, \text { where } P_{1} r_{2}-P_{2} r_{1} \neq 0 .
\end{aligned}
$$

Using the value $X_{2}$ from (35) in (39) we get,

$$
\begin{aligned}
& P_{1} X_{1}=B-P_{2}\left(\frac{P_{1} R-B r_{1}}{P_{1} r_{2}-P_{2} r_{1}}\right) \\
& X_{1}^{*}=X_{1}=\frac{B r_{2}-P_{2} R}{P_{1} r_{2}-P_{2} r_{1}}, \text { where } P_{1} r_{2}-P_{2} r_{1} \neq 0 .
\end{aligned}
$$

Equations (37) and (40) proved the theorem 2a.

Now using the value of $X_{2}$ from (38) in (35) we get, 

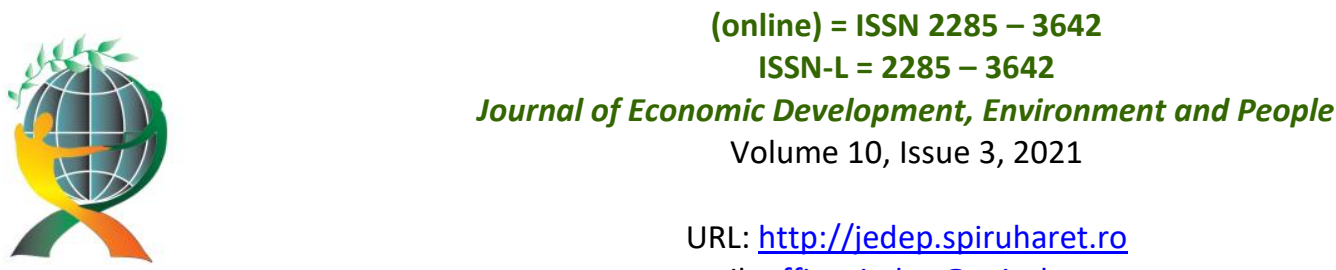

URL: http://jedep.spiruharet.ro

e-mail: office jedep@spiruharet.ro

$$
\begin{aligned}
& \gamma_{2}=\frac{B-2 P_{2}\left(\frac{B r_{2}-P_{2} R}{P_{1} r_{2}-P_{2} r_{1}}\right)}{P_{1} r_{2}-P_{2} r_{1}} \\
& \gamma_{2}^{*}=\gamma_{2}=\frac{B P_{1} r_{2}-R P_{1} P_{2}+B P_{2} r_{1}}{\left(P_{1} r_{2}-P_{2} r_{1}\right)^{2}}, \text { where } P_{1} r_{2}-P_{2} r_{1} \neq 0 .
\end{aligned}
$$

Now using the value of $X_{1}$ from (40) in (38) we get,

$$
\begin{aligned}
& \gamma_{1}=\frac{R-2 r_{1}\left(\frac{B r_{2}-P_{2} R}{P_{1} r_{2}-P_{2} r_{1}}\right)}{P_{1} r_{2}-P_{2} r_{1}} \\
& \gamma_{1}^{*}=\gamma_{1}=\frac{R P_{1} r_{2}+R P_{2} r_{1}-2 B r_{1} r_{2}}{\left(P_{1} r_{2}-P_{2} r_{1}\right)^{2}} \text {, where } P_{1} r_{2}-P_{2} r_{1} \neq 0 .
\end{aligned}
$$

Hence the theorem $2 b$ is proved.

Using the value $X_{2}$ from (35) and $X_{1}$ from (40) in (30) we get,

$$
\begin{gathered}
U=\frac{B r_{2}-P_{2} R}{P_{1} r_{2}-P_{2} r_{1}} \times \frac{P_{1} R-B r_{1}}{P_{1} r_{2}-P_{2} r_{1}} \\
U^{*}=\frac{B R\left(P_{1} r_{2}+P_{2} r_{1}\right)-B^{2} r_{1} r_{2}-P_{1} P_{2} R^{2}}{\left(P_{1} r_{2}-P_{2} r_{1}\right)^{2}}, \text { where } P_{1} r_{2}-P_{2} r_{1} \neq 0 .
\end{gathered}
$$

Hence theorem $2 \mathrm{c}$ is proved.

\section{Economic Analysis of Lagrange Multipliers}

In this section we shall try to interpret Lagrange multipliers. They are important in economics for the prediction of future utilities of the consumers. The producers can produce their products with confidence if they are confirmed about the consumers' future satisfaction. Depending on the utility a producer will increase or decrease his/her future budget in production. In the following theorem we will predict the necessary budget depending on the future utility of an individual [Islam et al., 2010].

Theorem 3: Prove that:

a) If an individual wants to increase (decrease) 1 unit of his utility, it would cause the total budget to increase (decrease) by approximately $\gamma_{1}^{*}$ units.

b) If an individual wants to increase (decrease) 1 unit of his utility, it would cause the total quantity of coupons to increase (decrease) by approximately $\gamma_{2}^{*}$ units.

Proof: Let us consider that the coupon constraint is constant. i.e., $d R=0$, then $\gamma_{2}=0$. From (30) we get,

$$
\begin{aligned}
& U_{1}=X_{2} \text { and } U_{2}=X_{1} . \\
& \frac{\partial U^{*}}{\partial B}=U_{1} \frac{\partial X_{1}}{\partial B}+U_{2} \frac{\partial X_{2}}{\partial B}
\end{aligned}
$$


Now we assume that $\gamma_{2}=0$, from $(32 b, c)$ we get,

$$
X_{1}=\gamma_{1} P_{2} \text { and } X_{2}=\gamma_{1} P_{1} \text {. }
$$

Using (46) in equation (45) we get,

$$
\left(\frac{\partial U^{*}}{\partial B}\right)_{R=\text { constant }}=\gamma_{1}\left(P_{1} \frac{\partial X_{1}}{\partial B}+P_{2} \frac{\partial X_{2}}{\partial B}\right) .
$$

Now we differentiate (32b) with respect to $B$ where $P_{1}$ and $P_{2}$ are constants, yields,

$$
1=P_{1} \frac{\partial X_{1}}{\partial B}+P_{2} \frac{\partial X_{2}}{\partial B} .
$$

Combining (47) and (48) we get,

$$
\left(\frac{\partial U^{*}}{\partial B}\right)_{R=\text { constant }}=\gamma_{1}^{*} .
$$

Equation (49) is same as (29c), i.e., marginal utility indicates that the change in total utility incurred from an additional unit of budget $B$. Hence, if an individual wants to increase (decrease) 1 unit of his utility, it would cause the total budget to increase (decrease) by approximately $\gamma_{1}^{*}$ units. Hence, theorem $3 a$ is proved.

Let us consider that the budget is constant. i.e., $d B=0$, then $\gamma_{1}=0$. From (30) we get,

$$
\begin{aligned}
& X_{2}=\gamma_{2} r_{1}, \text { and } X_{1}=\gamma_{2} r_{2} . \\
& \left(\frac{\partial U^{*}}{\partial R}\right)_{B=\text { constant }}=\gamma_{2}\left(r_{1} \frac{\partial X_{1}}{\partial R}+r_{2} \frac{\partial X_{2}}{\partial R}\right) .
\end{aligned}
$$

Now we differentiate (32c) with respect to $R$ where $r_{1}$ and $r_{2}$ are constants, and yields,

$$
1=r_{1} \frac{\partial X_{1}}{\partial R}+r_{2} \frac{\partial X_{2}}{\partial R}
$$

Comparing (51) and (52) we get,

$$
\left(\frac{\partial U^{*}}{\partial R}\right)_{B=\text { constant }}=\gamma_{2}^{*} .
$$

Equation (53) is same as equation (26), i.e., marginal utility indicates that the change in total utility incurred from an additional unit of coupon $R$. Hence, if an individual wants to increase (decrease) 1 unit of his utility, it would cause the total coupon to increase (decrease) by approximately $\gamma_{2}^{*}$ units. Hence, theorem $3 \mathrm{~b}$ is proved.

\section{Verification of Utility Maximization}

In this section we try to verify relative maximum of utility using the second-order sufficient conditions. Consider the bordered Hessian, 


$$
|H|=\left|\begin{array}{cccc}
0 & 0 & -B_{1} & -B_{2} \\
0 & 0 & -R_{1} & -R_{2} \\
-B_{1} & -R_{1} & U_{11} & U_{12} \\
-B_{2} & -R_{2} & U_{21} & U_{22}
\end{array}\right| .
$$

The critical values $X_{1}^{*}, X_{2}^{*}, \gamma_{1}^{*}$ and $\gamma_{2}^{*}$; then the stationary value of utility $U$ that is obtained in (42) must be maximum.

Theorem 4: Prove that the sufficient conditions for utility maximization is that the Hessian, $|H|>0$.

Proof: From (54) we get,

$$
\begin{aligned}
& |H|=-B_{1}\left|\begin{array}{ccc}
0 & 0 & -R_{2} \\
-B_{1} & -R_{1} & U_{12} \\
-B_{2} & -R_{2} & U_{22}
\end{array}\right|+B_{2}\left|\begin{array}{ccc}
0 & 0 & -R_{1} \\
-B_{1} & -R_{1} & U_{11} \\
-B_{2} & -R_{2} & U_{21}
\end{array}\right| \\
& =-B_{1}\left\{-R_{2}\left(B_{1} R_{2}-R_{1} B_{2}\right)\right\}+B_{2}\left\{-R_{1}\left(B_{1} R_{2}-R_{1} B_{2}\right)\right\} \\
& =B_{1}{ }^{2} R_{2}^{2}-2 B_{1} B_{2} R_{1} R_{2}+B_{2}{ }^{2} R_{1}^{2} .
\end{aligned}
$$

Taking partial derivatives and cross-partial derivatives of (30) and (32a, b) we get,

$$
\begin{aligned}
& B_{1}=P_{1}, B_{2}=P_{2}, R_{1}=r_{1}, R_{2}=r_{2} . \\
& U_{1}=X_{2}, U_{2}=X_{1}, U_{11}=0, U_{22}=0, U_{12}=U_{21}=1 .
\end{aligned}
$$

Using $(56 a, b)$ in (55) we get,

$$
\begin{aligned}
& |H|=P_{1}^{2} r_{2}^{2}+P_{2}^{2} r_{1}^{2}-2 P_{1} P_{2} r_{1} r_{2} \\
& =\left(P_{1} r_{2}-P_{2} r_{1}\right)^{2} .
\end{aligned}
$$

From (57) we observe that if $P_{1} r_{2}=P_{2} r_{1}$, then $|H|=0$, i.e., the Hesian matrix is singular and we avoid it. In this study we consider $P_{1} r_{2} \neq P_{2} r_{1}$. Equation (39) is a perfect square and $|H| \neq 0$, consequently, $|H|>0$. Hence, theorem 4 is proved.

\section{Prediction of Consumer Behaviors}

Now we can calculate the 24 partial derivatives; $\frac{\partial \gamma_{1}}{\partial P_{1}}, \cdots, \frac{\partial \gamma_{2}}{\partial P_{2}}, \cdots, \frac{\partial X_{1}}{\partial P_{2}}, \cdots, \frac{\partial X_{2}}{\partial P_{1}}$, etc. which are called the comparative statics of the model. Now by the implicit-function theorem we see that $X_{1}, X_{2}$, $\gamma_{1}$, and $\gamma_{2}$ will each be continuously differentiable functions of $P_{1}, P_{2}, r_{1}, r_{2}, B$, and $R$ if the Jacobian matrix, 

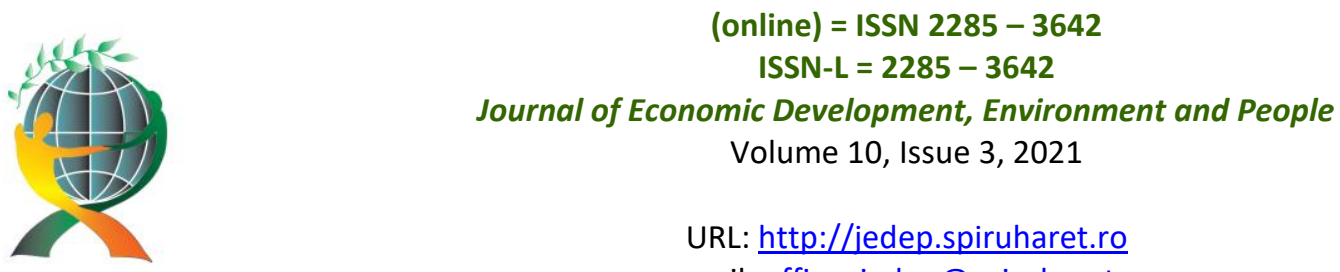

URL: http://jedep.spiruharet.ro

e-mail: office jedep@spiruharet.ro

$$
J=\left[\begin{array}{cccc}
0 & 0 & -B_{1} & -B_{2} \\
0 & 0 & -R_{1} & -R_{2} \\
-B_{1} & -R_{1} & U_{11} & U_{12} \\
-B_{2} & -R_{2} & U_{21} & U_{22}
\end{array}\right]
$$

is non-singular at the optimum point $\left(X_{1}^{*}, X_{2}^{*}, \gamma_{1}{ }^{*}, \gamma_{2}{ }^{*}\right)$. As second order conditions have been satisfied, so that $|J|=|H|$. We denote left hand sides of (32a-d) by four components of a vector $\mathbf{F}$, which all depend on $\gamma_{1}{ }^{*}, \gamma_{2}{ }^{*}, X_{1}^{*}, X_{2}^{*}, P_{1}, P_{2}, r_{1}, r_{2}, B$, and $R$; which may be regarded as points in a 10-dimensional Euclidian space, $E^{10}$. Thus, $\mathbf{F}=\left(F_{1}, F_{2}, F_{3}, F_{4}\right)$,

$$
F_{\alpha}=F_{\alpha}\left(\gamma_{1}^{*}, \gamma_{2}^{*}, X_{1}^{*}, X_{2}^{*}, P_{1}, P_{2}, r_{1}, r_{2}, B, R\right)=0 ; \alpha=1,2,3,4 \text {. }
$$

By the implicit function theorem, we solve (59) for the functions $\gamma_{1}^{*}, \gamma_{2}{ }^{*}, X_{1}^{*}$ and $X_{2}^{*}$ in terms of $P_{1}, P_{2}, r_{1}, r_{2}, B$, and $R$ as follows:

$$
\left[\begin{array}{l}
\gamma_{1} \\
\gamma_{2} \\
X_{1} \\
X_{2}
\end{array}\right]=\mathbf{G}\left(P_{1}, P_{2}, r_{1}, r_{2}, B, R\right),
$$

where $\mathbf{G}=\left(G_{1}, G_{2}, G_{3}, G_{4}\right)$ is a 4-vector valued functions of $P_{1}, P_{2}, r_{1}, r_{2} B$, and $R$. Moreover, the Jacobian matrix for $\mathbf{G}$, regarded as $J_{G}$ is given by,

$$
\begin{gathered}
J_{G}=\left[\begin{array}{llllll}
\frac{\partial \gamma_{1}{ }^{*}}{\partial P_{1}} & \frac{\partial \gamma_{1}{ }^{*}}{\partial P_{2}} & \frac{\partial \gamma_{1}^{*}}{\partial r_{1}} & \frac{\partial \gamma_{1}^{*}}{\partial r_{2}} & \frac{\partial \gamma_{1}^{*}}{\partial B} & \frac{\partial \gamma_{1}^{*}}{\partial R} \\
\frac{\partial \gamma_{2}{ }^{*}}{\partial P_{1}} & \frac{\partial \gamma_{2}{ }^{*}}{\partial P_{2}} & \frac{\partial \gamma_{2}{ }^{*}}{\partial r_{1}} & \frac{\partial \gamma_{2}{ }^{*}}{\partial r_{2}} & \frac{\partial \gamma_{2}{ }^{*}}{\partial B} & \frac{\partial \gamma_{2}{ }^{*}}{\partial R} \\
\frac{\partial X_{1}^{*}}{\partial P_{1}} & \frac{\partial X_{1}^{*}}{\partial P_{2}} & \frac{\partial X_{1}^{*}}{\partial r_{1}} & \frac{\partial X_{1}^{*}}{\partial r_{2}} & \frac{\partial X_{1}^{*}}{\partial B} & \frac{\partial X_{1}^{*}}{\partial R} \\
\frac{\partial X_{2}^{*}}{\partial P_{1}} & \frac{\partial X_{2}^{*}}{\partial P_{2}} & \frac{\partial X_{2}^{*}}{\partial r_{1}} & \frac{\partial X_{2}^{*}}{\partial r_{2}} & \frac{\partial X_{2}^{*}}{\partial B} & \frac{\partial X_{2}^{*}}{\partial R}
\end{array}\right] \\
=-J^{-1}\left[\begin{array}{cccccc}
-X_{1}^{*} & -X_{2}^{*} & 0 & 0 & 1 & 0 \\
0 & 0 & -X_{1}^{*} & -X_{2}^{*} & 0 & 1 \\
-\gamma_{1} & 0 & \gamma_{2} & 0 & 0 & 0 \\
0 & -\gamma_{1} & 0 & -\gamma_{2} & 0 & 0
\end{array}\right] .
\end{gathered}
$$

Here the $\mathrm{i}^{\text {th }}$ row of $(61)$ is obtained by differentiating the $\mathrm{i}^{\text {th }}$ left hand side in (32a-d) with respect to $P_{1}$, then $P_{2}$, then $r_{1}$, then $r_{2}$, then $B$, and then $R$. By the properties of matrix we can write, $J^{-1}=\frac{1}{|J|} C^{T}$, 


\section{(online) $=$ ISSN $2285-3642$ \\ ISSN-L = $2285-3642$ \\ Journal of Economic Development, Environment and People \\ Volume 10, Issue 3, 2021 \\ URL: http://jedep.spiruharet.ro \\ e-mail: office jedep@spiruharet.ro}

where $C=\left(C_{i j}\right)$, the matrix of cofactors of $J$ and $T$ indicates transpose. Hence equation in (59) can be written as,

$$
\begin{aligned}
& J_{G}=\frac{-1}{|J|} C^{T}\left[\begin{array}{cccccc}
-X_{1}^{*} & -X_{2}^{*} & 0 & 0 & 1 & 0 \\
0 & 0 & -X_{1}^{*} & -X_{2}^{*} & 0 & 1 \\
-\gamma_{1} & 0 & \gamma_{2} & 0 & 0 & 0 \\
0 & -\gamma_{1} & 0 & -\gamma_{2} & 0 & 0
\end{array}\right] \\
& =\frac{-1}{|J|}=\left[\begin{array}{llll}
C_{11} & C_{21} & C_{31} & C_{41} \\
C_{12} & C_{22} & C_{32} & C_{42} \\
C_{13} & C_{23} & C_{33} & C_{43} \\
C_{14} & C_{24} & C_{34} & C_{44}
\end{array}\right]\left[\begin{array}{cccccc}
-X_{1}^{*} & -X_{2}^{*} & 0 & 0 & 1 & 0 \\
0 & 0 & -X_{1}^{*} & -X_{2}^{*} & 0 & 1 \\
-\gamma_{1} & 0 & \gamma_{2} & 0 & 0 & 0 \\
0 & -\gamma_{1} & 0 & -\gamma_{2} & 0 & 0
\end{array}\right] \\
& =\frac{-1}{|J|}\left[\begin{array}{lllllll}
-X_{1}^{*} C_{11}-\gamma_{1}^{*} C_{31} & -X_{2}^{*} C_{11}-\gamma_{1}^{*} C_{41} & -X_{1}^{*} C_{21}-\gamma_{2}^{*} C_{31} & -X_{2}^{*} C_{21}-\gamma_{2}^{*} C_{41} & C_{11} & C_{21} \\
-X_{1}^{*} C_{12}-\gamma_{1}^{*} C_{32} & -X_{2}^{*} C_{12}-\gamma_{1}^{*} C_{42} & -X_{1}^{*} C_{22}-\gamma_{2}^{*} C_{32} & -X_{2}^{*} C_{22}-\gamma_{2}^{*} C_{42} & C_{12} & C_{22} \\
-X_{1}^{*} C_{13}-\gamma_{1}^{*} C_{33} & -X_{2}^{*} C_{13}-\gamma_{1}^{*} C_{43} & -X_{1}^{*} C_{23}-\gamma_{2}^{*} C_{33} & -X_{2}^{*} C_{23}-\gamma_{2}^{*} C_{43} & C_{13} & C_{23} \\
-X_{1}^{*} C_{14}-\gamma_{1}^{*} C_{34} & -X_{2}^{*} C_{14}-\gamma_{1}^{*} C_{44} & -X_{1}^{*} C_{24}-\gamma_{2}^{*} C_{34} & -X_{2}^{*} C_{24}-\gamma_{2}^{*} C_{44} & C_{14} & C_{24}
\end{array}\right] .
\end{aligned}
$$

Now we shall try to establish some economic relations in the following theorems that will predict the economic behaviors of the utility among the consumers. So that producers can take decision of their future productions accordingly.

Theorem 5: Prove that, $\frac{\partial X_{2}^{*}}{\partial P_{1}}=\frac{r_{1}\left(r_{2} B-P_{2} R\right)}{\left(P_{1} r_{2}-P_{2} r_{1}\right)^{2}}$, where $P_{1} r_{2} \neq P_{2} r_{1}$.

Proof: Now we try for $\frac{\partial X_{2}^{*}}{\partial P_{1}}$, i.e., if the price of commodity $x_{1}$ increases, the change of level of consumption of commodity $x_{2}$.

$$
\begin{aligned}
& \frac{\partial X_{2}^{*}}{\partial P_{1}}=\frac{-1}{|J|}\left[-X_{1}^{*} C_{14}-\gamma_{1}^{*} C_{34}\right] \\
& =\frac{-X_{1}^{*}}{|J|}\left[C_{14}\right]-\frac{\gamma_{1}^{*}}{|J|}\left[C_{34}\right] \\
& =\frac{-X_{1}^{*}}{|J|} \times \text { Cofactor of } C_{14}-\frac{\gamma_{1}^{*}}{|J|} \times \text { Cofactor of } C_{34} \\
& =\frac{-X_{1}^{*}}{|J|}\left|\begin{array}{ccc}
0 & 0 & -R_{1} \mid \\
-B_{1} & -R_{1} & U_{11} \\
-B_{2} & -R_{2} & U_{21}
\end{array}\right|-\frac{\gamma_{1}^{*}}{|J|}\left|\begin{array}{ccc}
0 & 0 & -B_{1} \\
0 & 0 & -R_{1} \\
-B_{2} & -R_{2} & U_{21}
\end{array}\right| .
\end{aligned}
$$




$$
\begin{aligned}
& =\frac{-X_{1}^{*}}{|J|}\left\{-R_{1}\left(B_{1} R_{2}-B_{2} R_{1}\right)\right\}-0 . \\
& =\frac{r_{2} B-P_{2} R}{P_{1} r_{2}-P_{2} r_{1}} \times \frac{1}{\left(P_{1} r_{2}-P_{2} r_{1}\right)^{2}} \times\left\{r_{1}\left(P_{1} r_{2}-P_{2} r_{1}\right)\right\}, \text { since }|J|=|H| \text { from (58) and also using the values }
\end{aligned}
$$
from $(56 \mathrm{a}, \mathrm{b})$ and $(40)$.

$$
=\frac{r_{1}\left(r_{2} B-P_{2} R\right)}{\left(P_{1} r_{2}-P_{2} r_{1}\right)^{2}} \text {, where } P_{1} r_{2} \neq P_{2} r_{1} \text {. }
$$

Hence, theorem 5 is proved.

Here $P_{1}, P_{2}, r_{1}, r_{2}, B, R>0$ and $P_{1} r_{2} \neq P_{2} r_{1}$ so that the sign of $\frac{\partial X_{2}^{*}}{\partial P_{1}}$ depends on $\left(r_{2} B-P_{2} R\right)$.

Economic Analysis 1: In (63) we face three situations as follows:

a) If $r_{2} B-P_{2} R>0$, then $\frac{\partial X_{2}^{*}}{\partial P_{1}}>0$. Hence, if the price of the commodity $x_{1}$ increases, the level of consumption of $x_{2}$ will increase, i.e., commodities $x_{1}$ and $x_{2}$ are substitutes, for example, tea and coffee. b) If $r_{2} B-P_{2} R<0$, then $\frac{\partial X_{2}^{*}}{\partial P_{1}}<0$. Hence, if the price of the commodity $x_{1}$ decreases, the level of consumption of commodity $x_{2}$ will decrease, i.e., commodities $x_{1}$ and $x_{2}$ are complementary, for example, students and school dresses.

c) If $r_{2} B=P_{2} R$, then $\frac{\partial X_{2}^{*}}{\partial P_{1}}=0$. Hence, if the price of the commodity $x_{1}$ increases, it seems no effect fall on the level of consumption of commodity $x_{2}$, i.e., commodities $x_{1}$ and $x_{2}$ are unrelated, for example, fruits and textbooks.

Theorem 6: Prove that, $\frac{\partial X_{1}^{*}}{\partial P_{1}}=-\frac{r_{2}\left(r_{2} B-P_{2} R\right)}{\left(P_{1} r_{2}-P_{2} r_{1}\right)^{2}}$, where $P_{1} r_{2} \neq P_{2} r_{1}$.

Proof: Now we try for $\frac{\partial X_{1}^{*}}{\partial P_{1}}$, i.e., the consumption of commodity $x_{1}$ change when its price increases. From (61) we can write,

$$
\begin{aligned}
& \frac{\partial X_{1}^{*}}{\partial P_{1}}=\frac{-1}{|J|}\left[-X_{1}^{*} C_{13}-\gamma_{1}^{*} C_{33}\right] \\
& =\frac{X_{1}^{*}}{|J|}\left[C_{13}\right]+\frac{\gamma_{1}^{*}}{|J|}\left[C_{33}\right]
\end{aligned}
$$




$$
\begin{aligned}
& =\frac{X_{1}^{*}}{|J|} \times \text { Cofactor of } C_{13}+\frac{\gamma_{1}^{*}}{|J|} \times \text { Cofactor of } C_{33} \\
& =\frac{X_{1}^{*}}{|J|}\left|\begin{array}{ccc}
0 & 0 & -R_{2} \\
-B_{1} & -R_{1} & U_{12} \\
-B_{2} & -R_{2} & U_{22}
\end{array}\right|+\frac{\gamma_{1}^{*}}{|J|}\left|\begin{array}{ccc}
0 & 0 & -B_{1} \\
0 & 0 & -R_{1} \\
-B_{2} & -R_{2} & U_{22}
\end{array}\right| \\
& =\frac{X_{1}^{*}}{|J|}\left\{-R_{2}\left(B_{1} R_{2}-B_{2} R_{1}\right)\right\}+0 \\
& =\frac{r_{2} B-P_{2} R}{P_{1} r_{2}-P_{2} r_{1}} \times \frac{1}{\left(P_{2} r_{2}-P_{2} r_{1}\right)^{2}} \times\left\{-r_{2}\left(P_{1} r_{2}-P_{2} r_{1}\right)\right\}, \text { since }|J|=|H| \text { from (57) and also using the }
\end{aligned}
$$
values from $(56 \mathrm{a}, \mathrm{b})$ and $(40)$.

$$
=-\frac{r_{2}\left(r_{2} B-P_{2} R\right)}{\left(P_{1} r_{2}-P_{2} r_{1}\right)^{2}}, \text { where } P_{1} r_{2} \neq P_{2} r_{1} \text {. }
$$

Hence theorem 6 is proved.

Economic Analysis 2: Equation (64) provides three incidents as follows:

a) If $r_{2} B-P_{2} R>0$, then $\frac{\partial X_{1}^{*}}{\partial P_{1}}<0$, i.e., if the price of commodity $x_{1}$ increases, the level of consumption of $x_{1}$ will decrease. Hence, commodity $x_{1}$ has many substitute goods; consequently if the consumers want to substitute when the price of commodity $x_{1}$ goes up.

b) If $r_{2} B-P_{2} R<0$, then $\frac{\partial X_{1}^{*}}{\partial P_{1}}>0$, i.e., even if the price of commodity $x_{1}$ increases, the level of consumption of $x_{1}$ will increase. It seems that commodity $x_{1}$ is superior goods in this situation and it has no other substitutes.

c) If $r_{2} B=P_{2} R$, then $\frac{\partial X_{1}^{*}}{\partial P_{1}}=0$, i.e., if the price of commodity $x_{1}$ increases, there seems to be no effect on the level of consumption of goods $x_{1}$. It seems that commodity $x_{1}$ is a necessity and it has neither complementary nor substitute goods.

Theorem 7: Prove that, $\frac{\partial X_{2}^{*}}{\partial r_{1}}=-\frac{P_{1}\left(r_{2} B-P_{2} R\right)}{\left(P_{1} r_{2}-P_{2} r_{1}\right)^{2}}$, where $P_{1} r_{2} \neq P_{2} r_{1}$.

Proof: Now we try for $\frac{\partial X_{2}^{*}}{\partial r_{1}}$, i.e., if the level of consumption of commodity $x_{2}$ change when the quantity of surrendering coupons for purchasing of the commodity $x_{1}$ increases. 


$$
\begin{aligned}
& \frac{\partial X_{2}^{*}}{\partial r_{1}}=\frac{-1}{|J|}\left[-X_{1}^{*} C_{24}-\gamma_{2}^{*} C_{34}\right] \\
= & \frac{X_{1}^{*}}{|J|}\left[C_{24}\right]-\frac{\gamma_{2}^{*}}{|J|}\left[C_{34}\right] \\
= & \frac{X_{1}^{*}}{|J|} \times \text { Cofactor of } C_{24}-\frac{\gamma_{2}^{*}}{|J|} \times \text { Cofactorof } C_{34} \\
= & \frac{X_{1}^{*}}{|J|}\left|\begin{array}{ccc}
0 & 0 & -B_{1} \\
-B_{1} & -R_{1} & U_{11} \\
-B_{2} & -R_{2} & U_{21}
\end{array}\right|-\frac{\gamma_{2}^{*}}{|J|}\left|\begin{array}{ccc}
0 & 0 & -B_{1} \\
0 & 0 & -R_{1} \\
-B_{2} & -R_{2} & U_{21} \mid
\end{array}\right| \\
= & \frac{X_{1}^{*}}{|J|}\left\{-B_{1}\left(B_{1} R_{2}-B_{2} R_{1}\right)\right\}-0 \\
= & \frac{r_{2} B-P_{2} R}{P_{1} r_{2}-P_{2} r_{1}} \times \frac{1}{\left(P_{1} r_{2}-P_{2} r_{1}\right)^{2}} \times\left\{-P_{1}\left(P_{1} r_{2}-P_{2} r_{1}\right)\right\}, \text { since }|J|=|H| \text { from (58) and also using the values }
\end{aligned}
$$
from $(56 a, b)$ and $(40)$.

$$
=-\frac{P_{1}\left(r_{2} B-P_{2} R\right)}{\left(P_{1} r_{2}-P_{2} r_{1}\right)^{2}}, \text { where } P_{1} r_{2} \neq P_{2} r_{1} \text {. }
$$

Hence, theorem 7 is proved.

Economic Analysis 3: Again we face similar three situations as follows:

a) If $r_{2} B-P_{2} R>0$, then $\frac{\partial X_{2}^{*}}{\partial r_{1}}<0$, i.e., if the number of surrendering coupons to purchase the commodity $x_{1}$ increases, the level of consumption of $x_{2}$ will decrease.

b) If $r_{2} B-P_{2} R<0$, then $\frac{\partial X_{2}^{*}}{\partial r_{1}}>0$, i.e., if the number of surrendering coupons to purchase the commodity $x_{1}$ increases, the level of consumption of $x_{2}$ will also increase.

c) If $r_{2} B=P_{2} R$, then $\frac{\partial X_{2}^{*}}{\partial r_{1}}=0$, i.e., if the number of surrendering coupons to purchase the commodity $x_{1}$ increases, there is no effect on the level of the consumption of goods $x_{2}$.

Theorem 8: Prove that, $\frac{\partial X_{1}^{*}}{\partial r_{1}}=-\frac{P_{2}\left(P_{2} R-r_{2} B\right)}{\left(P_{1} r_{2}-P_{2} r_{1}\right)^{2}}$, where $P_{1} r_{2} \neq P_{2} r_{1}$. 


\section{(online) $=$ ISSN $2285-3642$ \\ ISSN-L = $2285-3642$ \\ Journal of Economic Development, Environment and People \\ Volume 10, Issue 3, 2021 \\ URL: http://jedep.spiruharet.ro \\ e-mail: office jedep@spiruharet.ro}

Proof: Now we try for $\frac{\partial X_{1}^{*}}{\partial r_{1}}$, i.e., the level of consumption of commodity $x_{1}$ changes then situation of the effects of quantity of surrendering coupons. From (45) we get,

$$
\begin{aligned}
& \frac{\partial X_{1}^{*}}{\partial r_{1}}=\frac{-1}{|J|}\left[-X_{1}^{*} C_{23}-\gamma_{2}^{*} C_{33}\right] \\
& =\frac{-X_{1}^{*}}{|J|}\left[C_{23}\right]+\frac{\gamma_{2}^{*}}{|J|}\left[C_{33}\right] \\
& =\frac{-X_{1}^{*}}{|J|} \times \text { Cofactor of } C_{23}+\frac{\gamma_{2}^{*}}{|J|} \times \text { Cofactor of } C_{33} \\
& =\frac{-X_{1}^{*}}{|J|}\left|\begin{array}{ccc}
0 & 0 & -B_{2} \\
-B_{1} & -R_{1} & U_{12} \\
-B_{2} & -R_{2} & U_{22}
\end{array}\right|+\frac{\gamma_{2}^{*}}{|J|}\left|\begin{array}{ccc}
0 & 0 & -B_{2} \\
0 & 0 & -R_{2} \\
-B_{2} & -R_{2} & U_{22}
\end{array}\right| \text {. } \\
& =\frac{-X_{1}^{*}}{|J|}\left\{-B_{2}\left(B_{1} R_{2}-B_{2} R_{1}\right)\right\}+0 \text {. } \\
& =\frac{r_{2} B-P_{2} R}{P_{1} r_{2}-P_{2} r_{1}} \times \frac{1}{\left(P_{1} r_{2}-P_{2} r_{1}\right)^{2}} \times\left\{-P_{2}\left(P_{1} r_{2}-P_{2} r_{1}\right)\right\} \text {, since }|J|=|H| \text { from (58) and also using the values }
\end{aligned}
$$
from $(56 a, b)$ and $(41)$.

$$
=-\frac{P_{2}\left(P_{2} R-r_{2} B\right)}{\left(P_{1} r_{2}-P_{2} r_{1}\right)^{2}}, \text { where } P_{1} r_{2} \neq P_{2} r_{1} \text {. }
$$

Hence, theorem 8 is proved.

Economic Analysis 4: In (66) we face three situations as follows:

a) If $P_{2} R-r_{2} B>0$, then $\frac{\partial X_{1}^{*}}{\partial r_{1}}<0$, i.e., if the quantity of surrendering coupon to purchase the commodity $x_{1}$ increases, the level of consumption of $x_{1}$ will decrease. Hence, commodity $x_{1}$ has many substitutes; consequently the consumers move to substitutes when its quantity of surrendering rations coupons to purchase the commodity increases.

b) If $P_{2} R-r_{2} B<0$, then $\frac{\partial X_{1}^{*}}{\partial r_{1}}>0$, i.e., if the quantity of surrendering coupon to purchase the commodity $x_{1}$ increases, the level of consumption of $x_{1}$ will decrease. Obviously, commodity $x_{1}$ is superior and it has no other substitutes. 


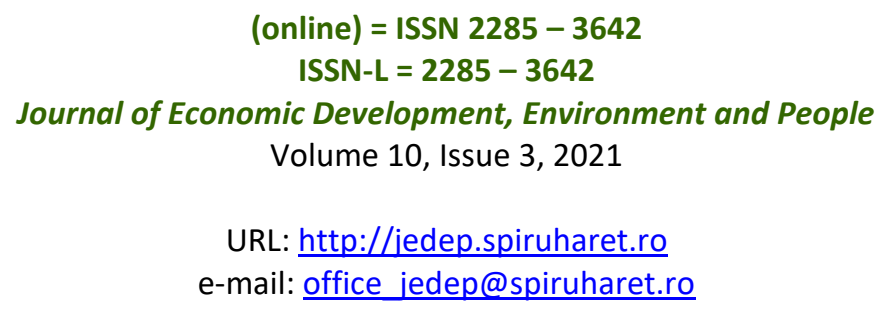

c) If $P_{2} R-r_{2} B=0$, then $\frac{\partial X_{1}^{*}}{\partial r_{1}}=0$, i.e., if the quantity of surrendering coupon to purchase the commodity $x_{1}$ increases, there is no effect on the level of the consumption of goods $x_{1}$. Hence, commodity $x_{1}$ is a necessity and it has neither complementary nor supplementary.

Theorem 9: Prove that, $\frac{\partial X_{1}^{*}}{\partial B}=\frac{r_{2}}{P_{1} r_{2}-P_{2} r_{1}}$, where $P_{1} r_{2} \neq P_{2} r_{1}$.

Proof: Now we see for $\frac{\partial X_{1}^{*}}{\partial B}$, a change in budget $B$, the effect of

$$
\begin{aligned}
& \frac{\partial X_{1}^{*}}{\partial B}=\frac{-1}{|J|}\left[C_{13}\right] \\
& =\frac{-1}{|J|} \times \text { Cofactor of } C_{13} \\
& =\frac{-1}{|J|}\left|\begin{array}{ccc}
0 & 0 & -R_{2} \\
-B_{1} & -R_{1} & U_{12} \\
-B_{2} & -R_{2} & U_{22}
\end{array}\right| \\
& =\frac{R_{2}}{|J|}\left(B_{1} R_{2}-B_{2} R_{1}\right) \text {. } \\
& =\frac{r_{2}}{\left(P_{1} r_{2}-P_{2} r_{1}\right)^{2}}\left(P_{1} r_{2}-P_{2} r_{1}\right) \text {. } \\
& =\frac{r_{2}}{P_{1} r_{2}-P_{2} r_{1}} \text {, where } P_{1} r_{2} \neq P_{2} r_{1} \text {. }
\end{aligned}
$$

Hence, theorem 9 is proved.

Economic Analysis 5: Here two possible situations arise:

a) If $P_{1} r_{2}-P_{2} r_{1}>0$, then $\frac{\partial X_{1}^{*}}{\partial B}>0$, i.e., if the budget increases, the level of consumption of commodity $x_{1}$ will also increase. Hence, commodity $x_{1}$ is superior.

b) If $P_{1} r_{2}-P_{2} r_{1}<0$, then $\frac{\partial X_{1}^{*}}{\partial B}<0$, i.e., even if the budget increases, but the level of consumption of commodity $x_{1}$ can decrease. Hence, the commodity $x_{1}$ is inferior.

Similar situation happen for $\frac{\partial X_{1}^{*}}{\partial R}$.

\section{Conclusions and Recommendations}




\author{
(online) $=$ ISSN $2285-3642$ \\ ISSN-L = $2285-3642$ \\ Journal of Economic Development, Environment and People \\ Volume 10, Issue 3, 2021 \\ URL: http://jedep.spiruharet.ro \\ e-mail: office jedep@spiruharet.ro
}

Utility can be defined as the total satisfaction received by consumers from consuming commodities. Utility is important in economics; and consumers know how to maximize their utility by allocating their money between multiple types of goods and services. Maximum utility of consumers can be accurately identified by the mathematical procedures. In this study we have tried to discuss some basic definitions related to the utility. Then we have elaborately discus the main body of the paper with detail mathematical analysis. In this study we have applied Lagrange multipliers method to maximize utility function subject to two constraints: budget constraint and coupon constraint. The related theorems and economic analyses that are added in the study will help the readers to understand the article with full interest. We hope the advanced researchers related to this field can work in this field very confidently and we hope our work will help them partially. If researchers criticize about the faults of our work, we can develop our future works with more enthusiasm.

\title{
References
}

[1] Allen, G. D. (1934). The Nature of Indifference Curves. The Review of Economic Studies, 1(2), 110-121.

[2] Alvino, L., Constantinides, E., \& Franco, M. (2018). Towards a Better Understanding of Consumer Behavior: Marginal Utility as a Parameter in Neuromarketing Research. International Journal of Marketing Studies, 10(1), 90-106.

[3] Bentham, J. (1780). An Introduction to the Principles of Morals and Legislation. CreateSpace Independent Publishing Platform.

[4] Cassels, J. W. S. (1981). Economics for Mathematicians. Cambridge University Press.

[5] Castro, L. C., \& Araujo, A. S. (2019). Marginal Utility and its Diminishing Methods. International Journal of Tax Economics and Management, 2(6), 36-47.

[6] Chisholm, H. (Ed.) (1911). Bentham Jeremy. Encyclopedia Britannica 3 (11 th $^{\text {th }}$.). Cambridge University Press.

[7] Coleman, J. S. \& Fararo, T. J. (1992). Rational Choice Theory. Nueva York: Sage.

[8] Creswell, J. W. (2011). Research Design: Qualitative, Quantitative and Mixed Method Approaches (4 ${ }^{\text {th }}$ Ed.). Los Angeles: Sage Publications.

[9] Dominick, S. (2008). Principles of Microeconomics. Oxford University Press, New Delhi.

[10] Fishburn, P. C. (1970). Utility Theory for Decision Making. Huntington, NY: Robert E. Krieger.

[11] Galiani, F. (1751). Della Moneta. Reprinted in: Collezioni Custodi Scrittori Classici Italiani di Economia Politica, 10.

[12] Gauthier, D. (1975). Reason and Maximization. Canadian Journal of Philosophy, 4(3), 411-433.

[13] Georgescu-Roegen, N. (1968). Utility, International Encyclopedia of the Social Sciences, Vol. 16. D. L. Sills (Ed.). New York: Macmillan and The Free Press.

[14] Hicks, J. R. (1932). The Theory of Wages. Macmillan \& Co., London.

[15] Islam, J. N., Mohajan, H. K., \& Moolio, P. (2009a). Preference of Social Choice in Mathematical Economics. Indus Journal of Management \& Social Sciences, 3(1), 17-38.

[16] Islam, J. N., Mohajan, H. K., \& Moolio, P. (2009b). Political Economy and Social Welfare with Voting Procedure. KASBIT Business Journal, 2(1), 42-66.

[17] Islam, J. N., Mohajan, H. K., \& Moolio, P. (2010). Utility Maximization Subject to Multiple Constraints. Indus 
(online) = ISSN $2285-3642$

ISSN-L = $2285-3642$

Journal of Economic Development, Environment and People

Volume 10, Issue 3, 2021

URL: $\underline{\text { http://jedep.spiruharet.ro }}$

e-mail: office jedep@spiruharet.ro

Journal of Management \& Social Sciences, 4(1), 15-29.

[18] Islam, J. N., Mohajan, H. K., \& Moolio, P. (2011). Output Maximization Subject to a Nonlinear Constraint. KASBIT Business Journal, 4(1), 116-128.

[19] Juster, F. T. (1990). Rethinking Utility Theory. The Journal of Behavioral Economics, 19(2), 155-179.

[20] Kirsh, Y. (2017). Utility and Happiness in a Prosperous Society. Working Paper Series, No. 37-2017, Institute for Policy Analysis, The Open University of Israel.

[21] Kothari, C. R. (2008). Research Methodology: Methods and Techniques (2 ${ }^{\text {nd }}$ Ed.). New Delhi: New Age International (P) Ltd.

[22] Kubler, F., Selden, L, \& Wei, X. (2014). Asset Demand Based Tests of Expected Utility Maximization. American Economic Review, 104(11), 3459-3480.

[23] Lin, C.-C., \& Peng, S.-S. (2019). The Role of Diminishing Marginal Utility in the Ordinal and Cardinal Utility Theories. Australian Economic Papers, 58(3), 233-246.

[24] Marshall, A. (1881). Review of F. Y. Edgeworth's Mathematical Psychics. The Academy, June 18, 1881.

[25] McConnell, C. R., Brue, S. L., \& Flynn, S. M. (2009). Economics: Principles, Problems, and Policies (8 ${ }^{\text {th }}$ Ed.). McGrawHill, Irwin, Boston.

[26] Mill, J. S. (1848). Principles of Political Economy with Some of Their Applications to Social Philosophy. London: John W. Parker.

[27] Mohajan, H. K. (2017a). Optimization Models in Mathematical Economics. Journal of Scientific Achievements, 2(5), $30-42$.

[28] Mohajan, H. K. (2017b). Analysis of Reciprocity and Substitution Theorems, and Slutsky Equation. Noble International Journal of Economics and Financial Research, 2(3), 54-75.

[29] Mohajan, H. K. (2017c). Two Criteria for Good Measurements in Research: Validity and Reliability. Annals of Spiru Haret University Economic Series, 17(3), 58-82.

[30] Mohajan, H. K. (2018). Qualitative Research Methodology in Social Sciences and Related Subjects. Journal of Economic Development, Environment and People, 7(1), 23-48.

[31] Mohajan, H. K. (2020). Quantitative Research: A Successful Investigation in Natural and Social Sciences. Journal of Economic Development, Environment and People, 9(4), 52-79.

[32] Mohajan, H. K. (2021a). Product Maximization Techniques of a Factory of Bangladesh: A Sustainable Procedure. American Journal of Economics, Finance and Management, 5(2), 23-44.

[33] Mohajan, H. K. (2021b). Estimation of Cost Minimization of Garments Sector by Cobb-Douglass Production Function: Bangladesh Perspective. Annals of Spiru Haret University Economic Series, 21(2), 267-299.

[34] Mohajan, H. K., Islam, J. N., \& Moolio, P. (2013). Optimization and Social Welfare in Economics. Lambert Academic Publishing, Germany.

[35] Moolio, P., Islam, J. N., \& Mohajan, H. K. (2009). Output Maximization of an Agency. Indus Journal of Management and Social Sciences, 3(1), 39-51.

[36] Moscati, J. (2013). Were Jevons, Menger and Walras Really Cardinalists? On the Notion of Measurement in Utility Theory, Psychology, Mathematics and other Disciplines, 1870-1910. History of Political Economy, 45(3), 373-414. 


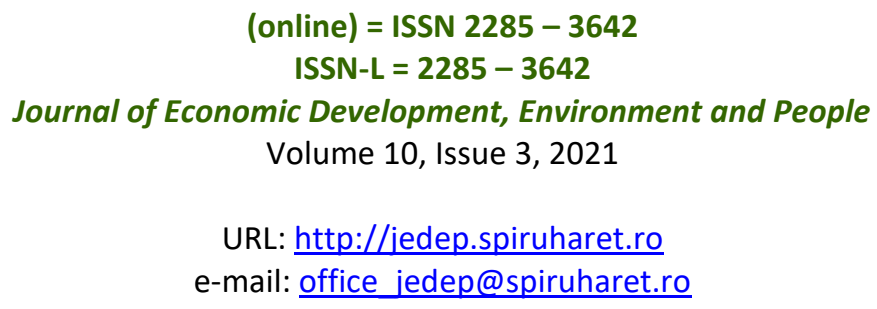

[37] Pareto, V. (1906). Manuale di Economia Politica, con una Introduzione alla Scienza Sociale. Societa Editrice Libraria, Milano.

[38] Polit, D. F., \& Hungler, B. P. (2013). Essentials of Nursing Research: Methods, Appraisal, and Utilization (8 $8^{\text {th }}$ Ed.). Philadelphia: Wolters Kluwer/Lippincott Williams and Wilkins.

[39] Read, D. (2004). Utility Theory from Jeremy Bentham to Daniel Kahneman. Working Paper No. LSEOR 04-64, London School of Economics and Political Science.

[40] Roy, L., Molla, R., \& Mohajan, H. K. (2021). Cost Minimization is Essential for the Sustainable Development of an Industry: A Mathematical Economic Model Approach. Annals of Spiru Haret University Economic Series, 21(1), 3769.

[41] Stigler, G. J. (1950). The Development of Utility Theory. I. Journal of Political Economy, 58(4), 307-327.

[42] Strotz, R. (1953). Cardinal Utility. American Economic Review, 43(2), 384-397.

[43] Swanson, R. A., \& Holton, E. F. III. (Eds.) (2005). Research in Organizations: Foundations and Methods of Inquiry. SanFrancisco: Berrett-Koehler.

[44] Waterfield, R. H. (Ed.) (1990). Conversations of Socrates by Xenophon. Penguin Classics, London.

[45] Zhao, Q., Zhang, Y., \& Friedman, D. (2017). Multi-Product Utility Maximization for Economic Recommendation. WSDM, 435-443. 